\title{
IDENTIDADES E A DIDATIZAÇÃO NA FORMAÇÃO DE PROFESSORES
}

\author{
Ieda Lourdes Gomes de Assumpsão* \\ Maicon Farias Vieira* \\ Leticia Fonseca Richthofen de Freitas ***
}

\begin{abstract}
RESUMO: Este trabalho tem como objetivo investigar como licenciandos de um curso de letras entendem a didática e a didatização como prática pedagógica na perspectiva decolonial. Pretende investigar, também, como a didática pode fomentar uma prática educativa de vanguarda a partir da análise de narrativas sobre como alunos de uma universidade privada lidam com tais conceitos, passam a operar com eles e constroem suas identidades docentes a partir da(s) linguagem(ns). Para tanto, nos embasamos no campo da Linguística Aplicada Indisciplinar, em sintonia com os estudos culturais, tendo como argumento a relação entre a linguagem e a produção de identidades, considerando a função que as narrativas desempenham no processo de construção identitária, no sentido de propor uma organização dos discursos nos espaços sociais. Sendo assim, a metodologia que se propõe está pautada na análise das narrativas dos licenciandos no processo de construção de conhecimentos a partir da utilização da didática. O resultado desta investigação quanto à formação de professores aponta indícios para refletir sobre a perspectiva da decolonialidade e sobre as identidades docentes como reflexo das performances narrativas da formação, das propostas e das estratégias formativas vivenciadas por meio das mediações didáticas promovidas ao longo do curso de formação dos sujeitos de pesquisa.
\end{abstract}

PALAVRAS-CHAVE: Decolonialidade; Didática; Formação de professores; Identidades; Narrativas.

\section{Introdução}

Lançar um olhar interpretativo sobre a didática e a didatização é, no mínimo, uma tarefa pretensiosa, no sentido da complexidade de pensar esta área de estudo da Pedagogia

\footnotetext{
* Docente do Instituto Superior de Formação Humanística da Universidade Católica de Pelotas. Mestre em Saúde e Comportamento. Doutoranda em Letras pela Universidade Federal de Pelotas (UFPel). Integrante do GPLANN - Grupo Pesquisa em Linguística Aplicada e Análise de Narrativas- PPGL - UFPel. Responsável pelo Núcleo de Estudos Pedagógicos do Curso de Pedagogia da UCPel. Interesses: Didática e decolonialidade; Formação de Professores; Pedagogia Universitária e Educação Inclusiva.

** Mestre em Educação pelo Instituto Federal Sul-Rio-Grandense (Ifsul) - Campus Pelotas. Doutorando em Letras pela Universidade Federal de Pelotas (UFPel).

*** Doutora em Educação pela Universidade Federal do Rio Grande do Sul (UFRS). Realizou estágio de PósDoutorado em Educação na UFRS e em Linguística Aplicada na Universidade Federal do Rio de Janeiro (UFRJ). Professora associada do Centro de Letras e Comunicação e do programa de Pós-Graduação em Letras da Universidade Federal de Pelotas (UFPel). Pesquisadora do Núcleo de Estudos Sobre Currículo Cultura e Sociedade do Programa de Pós-Graduação em Educação da UFRGS.
} 
e o processo de didatização que acontece no contexto do processo de ensino-aprendizagem.

Neste trabalho nos faremos valer da concepção de didática na perspectiva de Candau (2000, p. 14) que a demonstra a partir da "multidimensionalidade do processo de ensino-aprendizagem". São as diferentes dimensões presentes no processo de ensino e de aprendizagem, no contexto da prática educativa que se traduzem nos saberes ensinados e aprendidos. Queremos dizer com isso, conforme a autora, que o processo de ensino aprendizagem - objeto de estudo da didática - para ser entendido, necessita ser analisado de tal modo que "articule consistentemente as dimensões humana, técnica e político-social" (CANDAU, 2000, p. 14).

$\mathrm{Na}$ dimensão humana, o foco é a relação que se estabelece entre o professor e o aluno de modo a interferir sobre o vínculo, por meio da afetividade e da empatia, subsidiando a construção de conhecimentos. A dimensão técnica está centrada no estudo de recursos, ambientes e métodos que facilitem os processos de ensino-aprendizagem. $\mathrm{Na}$ dimensão político-social, apesar de não ser um "aspecto do processo ensino-aprendizagem" a didática "impregna toda a prática pedagógica" (CANDAU, 2000, p. 16), estando, assim, centrada na necessidade de realizar um ensino situado, atento ao contexto social e também atento aos condicionantes/alienantes da educação. Acrescentaríamos, também, a dimensão cultural: nessa última, que está centrada no respeito pelas diferentes identidades culturais (gênero, etnia, sexualidade, geração etc.) presentes na sala de aula e em sintonia com a urgência de se construir uma noção comum de partilha e solidariedade. É neste contexto complexo e multidimensional que queremos pensar, dialogar e lançar um olhar interpretativo no panorama da didática. E é pensando sobre os diálogos, insurgências, políticas, tensões, dimensões e perspectivas na relação com a formação docente que nos atrevemos a buscar um lugar de fala ${ }^{1}$ para investigar a formação docente por meio das narrativas.

${ }^{1}$ Por lugar de fala compreendemos as "realidades que foram consideradas implícitas dentro da normatização hegemônica, [o que não se trata] de afirmar as experiências individuais, mas de entender como o lugar social que certos grupos ocupam restringem oportunidades" (RIBEIRO, 2017, p. 60-61). 
Não há como negar a impactante interferência dos diversos setores (econômico, político e sociocultural) em nossas vidas, pois vivemos um período ditado pela contradição, pela normatividade, pelo gerencialismo, pela velocidade das tecnologias de informação e comunicação. Vemos, com isso, a urgência de estarmos atentos ao que vem sendo deliberado por esta interferência e que se manifesta nos discursos dos diversos espaços institucionais de formação regular. Queremos dizer que vivemos um complexo contexto global, que interfere no local, exigindo novas atitudes que possam alavancar novos diálogos para antigas e novas práticas pedagógicas, "questionando verdades naturalizadas em todos os sentidos, embora possam também confirmá-las, já que, como sabemos, são muitos os discursos que nos chegam" (MOITA LOPES, 2006, p. 91-92).

Porém, como nos questiona Moita Lopes, "como pensar novas formas de produzir conhecimento com base em outros olhares e, assim, colaborar na reinvenção da vida social" (2006, p. 94)? A abordagem proposta por esta investigação busca responder a este questionamento com um olhar para a formação de professores, experienciado por meio da didática e da didatização ${ }^{2}$ nas identidades que são performadas nos corpos em movimento ${ }^{3} \mathrm{em}$ espaços vivenciados pelas atividades educativas.

Estas considerações iniciais servem de fonte para problematizar as transformações ocorridas no espaço educativo pela maneira como as técnicas, a economia, a política e a sociedade reconfiguram e interferem na morfologia do espaço educativo. Estabelecer um diálogo com as principais abordagens da didática para compreender como elas se configuram e se inscrevem nas histórias de vida de alunos no seu contexto de formação é tema fértil no processo de desenvolvimento dos fundamentos pedagógicos.

${ }^{2} \mathrm{~A}$ didatização é entendida, aqui, como parte da Didática dentro do processo de ensino e aprendizagem, pois figura como a própria experiência docente. Pode-se considerar o fazer dos licenciados como uma prática didáticopedagógica, no que se refere aos saberes que são aprendidos e ensinados no propósito da transposição didática, bem como no diálogo da teoria com a prática.

${ }^{3}$ Entendemos corpos em movimento como uma metáfora para pensar nos sujeitos de pesquisa, os licenciandos que estão em processo de formação, e o quanto estas identidades vão se constituindo na medida que estes corpos se movimentam nesta formação inicial de professores. 
Esta inquietação é um desafio lançado a partir deste artigo: como estabelecer um diálogo e transpor o prescritivismo, as ideias fixas em uma teoria da didática contemporânea? Para responder, partimos da ideia lançada pelo manifesto de docentes no XIX ENDIPE (2018) ${ }^{4}$ de que “a didática existe, resiste e se reinventa a favor da educação", concomitante à formação dos professores, neste descaminho de efervescência nacional. Acredita-se que os recortes que serão propostos sobre o fenômeno educativo possam instigar outros olhares, e com isso seja possível rever e reconstruir processos envolvidos na formação de professores. Desse modo, objetivamos com este estudo investigar como a didática pode facultar uma prática educativa de vanguarda, não normativa, decolonial.

Ao utilizarmos o termo "decolonial" nos remetemos a "uma práxis baseada na insurgência educativa propositiva - portanto não somente denunciativa [...] onde o termo insurgir representa a criação e construção de novas condições sociais, políticas e culturais e de pensamento" (OLIVEIRA, 2016, p. 37). Cabe lembrar que as abordagens decoloniais buscam desconstruir "a naturalização do imaginário do invasor europeu, a subalternização epistêmica do outro não europeu e a própria negação e o esquecimento de processos históricos não-europeus" (OLIVEIRA; CANDAU, 2010, p. 19). Nesse sentido, quando defendemos uma pedagogia e uma didática decolonial, entendemos que é necessário ir além de mudanças metodológicas e/ou curriculares, pois, como apontam Oliveira e Candau, a perspectiva decolonial decorre de uma transformação sócio-histórica e estrutural que desloca a hegemonia epistemológica da modernidade europeia.

A decolonialidade pode ser utilizada como "uma estratégia que vai além da transformação da descolonização, ou seja, supõe também construção e criação. Sua meta é a reconstrução radical do ser, do poder e do saber" (OLIVEIRA; CANDAU, 2010, p. 25). Nessa perspectiva e para análise da pesquisa, a intenção é problematizar a didática e a didatização como possibilidade de um saber-fazer docente decolonial, crítico, criativo e emancipatório.

${ }^{4}$ ENDIPE é o Encontro Nacional de Didática e Prática de Ensino que acontece a cada dois anos. Disponível em https://endipesalvador.ufba.br/manifesto-de-docentes-acerca-da-didatica. Acesso em: 25 abr. 2020 


\section{Algumas trilhas para os saberes ensinados e aprendidos}

A educação, entendida como "uma pedagogia concebida como política cultural" (OLIVEIRA, 2016, p. 37), requer não apenas a apresentação de alternativas, mas, principalmente, a proposição de questionamentos que conduzam à reflexão. Assim, nos propomos as seguintes perguntas: de que maneira a didática e seu reflexo na didatização podem facultar uma prática educativa decolonial? Como a didática vem produzindo discursos, narrativas, e essas constituindo identidades? É possível redimensionar a própria prática pedagógica tradicional e repensar a didática prescritiva, normativa rumo ao movimento complexo/cambiante entre o pensar e o fazer? Seria possível pensar numa didática não normativa, decolonial, pós-didática?

Ressaltamos que este estudo se coloca na posição de fazer perguntas e provocar reflexões e não simplesmente criar uma receita e conceber verdades. Conforme salienta Veiga Neto (1996), também argumentamos no sentido de que esta

[...] será uma reflexão inacabada, uma reflexão que não coloca ponto final em nada, mas que, mesmo dando algumas respostas, cria muitas outras perguntas. Um dos meus interesses é exatamente esse: dar algumas respostas e criar outras perguntas. (VEIGA NETO, 1996, p. 163)

Assim, fazemos nossas as palavras de Veiga Neto e buscamos um viés para relacionar a didática e a atividade de didatização com a Linguística Aplicada (LA) Indisciplinar/Transgressiva ${ }^{5}$, com base no que refere Pennycook (2006), de que a LA Trangressiva vai além dos limites normativos, pois procura imaginar outras formas de atravessar fronteiras, de quebrar regras numa posição reflexiva sobre o quê e o porquê atravessa e sobre os modos de pensar sobre o uso da linguagem. Tendo como base Fabricio, ressalta-se que a linguagem implica "um conjunto de relações em permanente flutuação, por entender que

\footnotetext{
${ }^{5}$ Os termos Linguística Aplicada Indisciplinar e Linguística Aplicada Transgressiva serão utilizados ao longo da escrita como sinônimos. Para um maior aprofundamento, consultar Moita Lopes (2006).
} 
ela é inseparável das práticas sociais e discursivas que constroem, sustentam ou modificam as capacidades produtivas, cognitivas e desejantes dos atores sociais" (2006, p. 48).

As diferentes sustentações e práticas sociais presentes nos olhares da didatização se constroem a partir de diversos atravessamentos dos mais variados campos de saber para, enfim, constituir a prática da didática - isso acontece de forma análoga na LA Indisciplinar. Essa última "precisa ter algo a dizer sobre o mundo como se apresenta e que o faz com base nas discussões que estão atravessando outros campos das ciências sociais e das humanidades" (MOITA LOPES, 2006, p. 96). A realização de tal feito promove uma área mestiça, antidisciplinar e/ou indisciplinar, como ocorre com a didática. Moita Lopes chama a atenção, em relação à LA, para a necessidade de justamente se considerar tais atravessamentos e tal hibridismo: "Caso contrário, continuaremos a focalizar a linguagem e quem a usa em um vácuo social, sem vida cultural, histórica e política” (2004, p. 164).

Percebemos a didática de vanguarda na relação com a LA Trangressiva, uma vez que as duas vertentes teóricas sinalizam pensar de outro modo, numa posição reflexiva, por imaginar outras formas de atravessar fronteiras e, como já dito, sobre os modos de pensar o uso da linguagem. Além desta sinalização, podemos apontar o quanto a linguagem está atrelada à noção de narrativa entendida como prática social, local e não neutra para a (re)construção identitária. A (re)construção identitária passa pela compreensão das identidades como elementos não permanentes. Assim, "a identidade torna-se uma 'celebração móvel": formada e transformada continuamente em relação às formas pelas quais somos representados ou interpelados nos sistemas culturais que nos rodeiam (HALL, 2015, p. 11 12). Com isso, outras identidades, novos corpos, vão se constituindo. Logo, toda investigação reflete a nossa passagem pelo mundo, um corpo contextualizado, conectado com as coisas, com a vida. Ao abordar a assim chamada virada somática, Pennycook (2006), baseado em diversos autores, sublinha que a construção social está alicerçada na linguagem, mas ela apresenta um caráter corpóreo, já que está atravessada por diferenças raciais, sexuais, de gênero, entre outras. 
Em sintonia com as ideias de Pennycook, destacamos a relação existente entre a linguagem e a produção de identidades, considerando a função que as narrativas desempenham no processo de construção identitária, no sentido de organizar o discurso no mundo social (MOITA LOPES, 2001). Esse papel organizador do discurso, desempenhado pelas narrativas, a partir das histórias que contamos sobre nós e sobre os outros a fim de se fazer "um sentido da vida", possibilita a construção de um conhecimento sobre quem somos e quem são os outros, constituindo identidades individuais e sociais. Arfuch (2010) aponta também para a dimensão da narrativa enquanto configurativa da experiência humana. Nesse sentido, destacamos a função das narrativas como potência na constituição das identidades individuais e coletivas: o processo de escuta e de fala produz nossas identidades. Portanto, a relação entre linguagem, identidades, narrativas e a didática é no sentido de estarem "tecidas" e entrelaçadas.

Com base então nos argumentos acima, considera-se de extrema importância o estudo dos processos identitários que constituem o professor em formação. Conforme ressalta Nóvoa (1995)

\begin{abstract}
A identidade não é um dado adquirido, não é uma propriedade, não é um produto. A identidade é um lugar de lutas e de conflitos, é um espaço de construção de maneiras de ser e de estar na profissão. Por isso, é mais adequado falar em processo identitário, realçando a mescla dinâmica que caracteriza a maneira como cada um se sente e se diz professor. (NÓVOA, 1995, p. 16)
\end{abstract}

Nesse sentido, e considerando que as identidades são construídas por meio da linguagem, a partir das narrativas que contamos, passaremos, a seguir, à análise das narrativas de dois alunos do curso de Letras.

Como afirma Baptista (2019):

[...] o conhecimento se produz desde um determinado lócus enunciativo, e, no caso que nos interessa, como educadores e linguistas aplicados, esse espaço, contemporaneamente, tem gerado possibilidades outras para problematizarmos as práticas de linguagem, as identidades e as interrelações entre ambas. (BAPTISTA, 2019, p. 125) 
No campo metodológico optamos pela abordagem qualitativa, esta significa procurar maior aproximação com a realidade, um campo fértil para as interpretações da reconstrução do fenômeno educativo vivenciado por licenciandos em curso de licenciatura em uma universidade privada. Assim, acreditamos que esta abordagem caminha/aponta na perspectiva de uma didática viva, a qual se constrói em comunhão.

\section{Insurgências e emergências nas trilhas da pesquisa...}

A pesquisa desenvolvida se insere em uma abordagem qualitativa, tendo sido utilizados como procedimentos metodológicos a pesquisa bibliográfica e a análise de narrativas obtidas através de entrevistas semiestruturadas. Definimos como sujeitos de pesquisa alunos do Curso de Licenciatura em Letras já aprovados na disciplina de Didática. Para este trabalho foram escolhidas as narrativas de dois sujeitos. A pesquisa foi desenvolvida a partir das seguintes etapas:

a) Criação de um grupo no Whatsapp para facilitar os passos a serem realizados:

i. Assistir a um vídeo do programa Diálogos da UNB'.

ii. Ler o texto "O que é uma educação decolonial”? (Oliveira, 2016).

iii. Discussão com o grupo.

b) Entrevista.

O passo de assistir ao vídeo serviu como um material contextualizador, uma introdução ao tema. Como auxílio à produção visual, foi proposta a leitura do texto de Oliveira (2016), buscando fazer com que os sujeitos da pesquisa aproximassem os seus fazeres pedagógicos das conceituações do autor. A discussão proporcionou um espaço de troca de vivências e de ideias, o que possibilitou articular o suporte teórico do vídeo e do texto às práticas que alguns dos alunos já possuíam.

A entrevista buscou compreender, na opinião dos sujeitos pesquisados, como seria uma didática capaz de viabilizar uma perspectiva da decolonialidade. A coleta de dados 
deu-se através de entrevista narrativa (BASTOS e SANTOS, 2013, p. 21), que buscou investigar a prática pedagógica dos acadêmicos em relação ao entendimento de uma didática como alternativa para viabilizar a decolonialidade. Foi realizada a gravação das produções para análise posterior, cuja transcrição permitiu a utilização do modelo conhecido como análise de narrativa, que se caracteriza pelo "uso de histórias como dados" (PAIVA, 2019, p. 88), a fim de perscrutar o processo de formação e de constituição do sujeito profissional que se revela nestas histórias contadas e vividas, nestas identidades, nestes corpos em movimento.

Dentre as abordagens do pensamento da didática, os estudos de Candau e Oliveira (2010), Veiga Neto (2010), Walsh (2013) e outros colaboram com perspectivas para pensar a didática sob o viés vanguardista, não-normativo, decolonial ao sugerirem a compreensão de movimento e de não estagnação do conhecimento. Argumentamos, com base nas ideias dos referidos autores, que há possibilidades de relacionar a didática dentro de uma perspectiva da decolonialidade para defender uma prática educativa de vanguarda. Sendo assim, ao utilizamos um grupo de universitários como sujeitos desta pesquisa, buscamos examinar como são percebidos por estes sujeitos os efeitos da didatização nas suas formações docentes, como veremos a seguir.

Para dar conta disso, inicialmente, as alunas assinaram um termo de consentimento livre e esclarecido para utilização dos dados. Visando manter o sigilo das identidades das participantes, seus nomes não serão divulgados, apenas as chamaremos de alunas D e M.

Após a assinatura do termo, as alunas atenderam às etapas de visualização do vídeo, leitura do texto e discussão em grupo. Em seguida, na entrevista, as duas acadêmicas narraram desconhecer o termo decolonialidade. No entanto, a aluna M refletiu que as práticas realizadas durante a formação universitária são decoloniais, mas que nunca foram abordadas por este viés. Nesse sentido, mencionaram a questão de apagamentos, nas práticas pedagógicas, referentes a questões sociais importantes, como em relação à religiosidade e à masculinidade tóxica. A seguir, podemos observar como se manifestaram as alunas, a partir de excertos de suas narrativas: 


\section{Excerto 1}

Aluna M: Pensando no ensino de Literatura, geralmente a gente só fala de escritores homens brancos, a gente não fala sobre escritoras mulheres, no máximo Clarice Lispector, e negros também não... eu acho que eu puxaria muito para esse lado... e também, por exemplo, a gente vive na América Latina e a gente só vê, de Literatura Latina, a Literatura Brasileira mesmo né... eu não faço nem ideia [...] de outros escritores latinos [...] eu acho que eu tentaria buscar esses autores que são invisibilizados... para que o aluno possa talvez se sentir identificado, porque a gente não trabalha isso também, a identificação. A mulher, por exemplo, ela pode não se identificar com todos esses escritores, com todas as obras que eu estou trazendo porque elas são majoritariamente masculinas.

\section{Excerto 2}

Aluna D: Eu penso que se eu fosse trabalhar, eu buscaria bastante trabalhar com discussões em sala de aula [...] porque às vezes eles não têm noção sobre temas como religiosidade, cultura, variantes da língua, por exemplo. [...] Na religiosidade, por exemplo, quando os portugueses chegaram aqui, os povos indígenas tinham sua religiosidade e sua cultura, e hoje a gente não vê nada disso. Está, tipo, completamente apagado para quem não é indígena. Então acredito que seria bem importante trabalhar isso com os alunos todos. Eu achei esse termo bem interessante porque muitas vezes o outro não é dito... e o outro tem que ser dito.

Em ambos os casos, as alunas demonstram ter identificado alguns aspectos do pensamento decolonial, caracterizando-o como uma via alternativa marcada pela pluralidade na construção do pensamento e, por consequência, dos espaços de interação social. Nesse sentido, elas apontam questões de gênero, de geopolítica do conhecimento (dentro da literatura), e de religiosidade como pontos sobre os quais devemos refletir, uma vez que a lógica colonial se faz com base no sujeito masculino branco, cristão, europeu, heterossexual. No que se refere ao gênero, M enfatiza a abordagem acadêmica calcada em obras escritas por homens brancos; quanto à religiosidade, D salienta que as religiões indígenas foram apagadas da hegemonia da religiosidade europeia; e sobre Literatura Latina, M destaca que é a Literatura Brasileira (que, a rigor, já tem espaço em outras disciplinas do curso de Letras) que é ensinada, em detrimento de outros olhares. Vale ressaltar uma ideia apresentada por D e que demonstra sua compreensão a respeito de como a lógica da colonização epistemológica ainda está presente: “muitas vezes o outro não é dito... e o outro tem que ser dito". Pode-se argumentar, com base nos excertos das narrativas, que um primeiro passo em relação a uma abordagem decolonial é dado, uma vez que "decolonialidade é visibilizar as lutas contra a colonialidade a partir das pessoas, das suas práticas sociais, epistêmicas e políticas (OLIVEIRA; CANDAU, 2010, p. 24). 
Ademais, as narrativas das alunas permitem compreender não apenas o lugar de fala de cada uma - expresso nas posições de mulheres, acadêmicas do curso de Letras, com trajetórias distintas, mas, também, os lugares de enunciação trazidos por suas narrativas, como a falta de estudos sobre escritoras e a não discussão dos autores latinos não lusófonos - no caso da aluna $\mathrm{M}$ - e as relações de religiosidades e constituição do outro nos discursos - no caso da aluna D. Dessa maneira, as relações decoloniais não apenas são demonstradas nas narrativas, como remontam ao lugar de fala de cada uma, constituintes das "realidades que foram consideradas implícitas dentro da normatização hegemônica (RIBEIRO, 2017, p. 60), e aos lugares de enunciação. Justificado pelas palavras de Baptista (2019), o lugar de enunciação:

[...] conforma como um espaço de tensões que abarca diferentes identidades do sujeito, sendo atravessado por diversos movimentos constitutivos das dinâmicas das interações sociais; como tal, demarca fronteiras, rupturas e deslocamentos relevantes que nos permitem entrever a porosidade de construtos como sujeito, cultura, identidade e línguas que, no arcabouço epistemológico da colonialidade/modernidade, foram fixados e determinados como absolutos sob os olhares epistemológicos da racionalidade ocidental. (BAPTISTA, 2019, p. 124-125)

As informantes demonstraram conhecer alguns dos fundamentos do pensamento decolonial, indo ao encontro da proposição já mencionada por Oliveira, de que a decolonialidade é "uma práxis baseada na insurgência educativa propositiva - portanto não somente denunciativa" (2016, p. 37). Ao não se colocarem apenas na posição de denunciantes das ações, mas sim como sujeitos que denunciam e propõem condutas autoformativas, o que pode ser observado nos trechos "eu acho que eu puxaria muito para esse lado", no caso da aluna $\mathrm{M}$; e na narrativa da aluna D: "eu penso que se eu fosse trabalhar, eu buscaria bastante trabalhar com discussões em sala de aula" e "eu achei esse termo bem interessante porque muitas vezes o outro não é dito... e o outro tem que ser dito".

Outro ponto levantado nas narrativas das alunas e que merece destaque diz respeito “à construção de uma noção e visão pedagógica que se projeta muito além dos processos de ensino e de transmissão de saber, que concebe a pedagogia como política cultural. (OLI- 
VEIRA; CANDAU, 2010, p. 28). Assim, a aluna D alega que "na religiosidade, por exemplo, quando os portugueses chegaram aqui, os povos indígenas tinham sua religiosidade e sua cultura, e hoje a gente não vê nada disso. Está, tipo, completamente apagado para quem não é indígena”. Já na narrativa de M há a seguinte observação: "eu acho que eu tentaria buscar esses autores que são invisibilizados... para que o aluno possa talvez se sentir identificado, porque a gente não trabalha isso também, a identificação”.

Ambas, mesmo que de maneira incipiente, demonstram a compreensão de que, em uma perspectiva decolonial, é central que a noção de pedagogia contemple aspectos de uma política cultural, que engloba transformações mais profundas nas formas de conhecer e de ser. Ainda que no âmbito deste trabalho só tenham sido levantados dois excertos de narrativas, é possível começar a pensar em uma abordagem que leve em conta a perspectiva decolonial nos cursos de licenciatura, pois, conforme pudemos verificar, com base no trabalho realizado e descrito aqui, já foi possível que as alunas tenham entendido tal perspectiva e apontado caminhos para sua realização. Essa perspectiva colabora para a constituição das identidades docentes das alunas, possibilitando uma certa maneira de ser e de estar no mundo e na sala de aula.

\section{Trilhas das aprendizagens que não cessam....}

O resultado desta investigação aponta indícios para refletir sobre a perspectiva da decolonialidade como reflexo da formação por meio das propostas e das estratégias formativas vivenciadas pelas mediações didáticas no sentido da didatização promovidas ao longo do curso de formação dos sujeitos de pesquisa. Pensar a didática é um aprendizado em movimento, pois a didática deve ser entendida como obra e produto cumulativo do passado que tece o presente e abre caminhos ao futuro.

A didática se reflete em uma espécie de "teia e tessitura" que representa as muitas combinações das influências econômicas, políticas e culturais que são o alimento para a configuração de modos de vida que reverberam na atividade docente. Portanto, acreditase nas possibilidades de defender uma "nova" perspectiva, na trilha de revisitar a didática como premissa para novos desdobramentos no âmbito do planejamento pedagógico sob 
um olhar decolonial no sentido de visibilizar as lutas contra toda forma de invisibilidade e opressão.

Conforme ressalta Walsh (2009, p. 16), "nos referimos a uma práxis pedagógica crítica, intercultural e decolonial que pretende pensar não somente 'a partir' das lutas dos povos historicamente subalternizados, mas também 'com' sujeitos, conhecimentos e modos distintos de estar, de ser e de viver ${ }^{7 "}$. A proposta deste trabalho encaminha para a reflexão sobre a construção de uma didática e de uma pedagogia decoloniais na formação de alunos de cursos de licenciatura, argumentando que este é um caminho para a formação de professores que depois possam, em suas práticas, desconstruir subjetividades, imaginários e epistemologias coloniais, tão presentes ainda na teoria e na prática pedagógica.

\section{IDENTIDADES Y DIDATIZACIÓN EN LA FORMACIÓN DE PROFESORES}

RESUMEN: Este trabajo posee como objetivo averiguar cómo licenciandos de un curso de letras comprenden la didáctica y la didactización como práctica pedagógica en la perspectiva decolonial. Pretende investigar, también, cómo la didáctica puede fomentar una práctica educativa de vanguardia a partir de una análisis de narrativas sobre como alumnos de una universidad privada lidian con tales conceptos, operan con ellos y construyen sus identidades docentes a partir del (de los) lenguaje(s). Para tanto, nos basamos en el campo de la Lingüística Aplicada Indisciplinar, en sintonía con los estudios culturales, teniendo como argumentación la relación entre el lenguaje y la producción de identidades, considerando la función que las narrativas desempeñan en el proceso de construcción identitaria, en el sentido de proponer una organización de los discursos en los espacios sociales. Así, la metodología que proponemos está pautada en el análisis de las narrativas de los licenciandos en el proceso de construcción de conocimiento a partir de la utilización de la didáctica. El resultado de esta investigación cuanto a la formación de profesores apunta indicios para reflexionar sobre la perspectiva de la decolonialidad y sobre las identidades docentes como reflejo de las performances narrativas de formación, de las propuestas y de las estrategias formativas vividas mediante intermediación didáctica promovidas a lo largo del curso de formación de sujetos de investigación.

PALABRAS CLAVE: Identidades, Formación de profesores, Didáctica, Decolonialidad, Narrativas.

\footnotetext{
${ }^{7}$ Tradução dos autores do trabalho. Citação original: "Nos referimos a una praxis pedagógica crítica, intercultural y de-colonial que pretende pensar no sólo "desde" las luchas de los pueblos históricamente subalternizados, sino también "con" sujetos, conocimientos y modos distintos de estar, ser y vivir".
} 


\section{REFERÊNCIAS}

ARFUCH, Leonor. O espaço biográfico: Dilemas da subjetividade contemporânea. Rio de Janeiro: EdUERJ, 2010.

BAPTISTA, Lívia Márcia Tiba Rádis. (De)Colonialidade da linguagem, lócus enunciativo e constituição identitária em Gloria Anzaldúa: uma "new mestiza". Polifonia, Cuiabá: PPGEL/UFMT, v. 26, n. 44, p. 123-145, out./dez. 2019.

BASTOS, Liliana Cabral; SANTOS, William Soares. A entrevista na pesquisa qualitativa: perspectiva em análise da narrativa e da interação. Rio de Janeiro: FAPERJ, 2013.

CANDAU, Vera Maria. A didática e a formação de educadores - Da exaltação à negação: a busca da relevância. In: (Org.). A didática em questão. 18. ed. Petrópolis: Vozes, 2000. p. 13-24.

FABRICIO, Branca Falabella. Linguística aplicada como espaço de "desaprendizagem": redescrições em curso. In: MOITA LOPES, Luiz Paulo da (Org.). Por uma linguística aplicada INdisciplinar. 1. ed. São Paulo: Parábola, 2006. p. 45-65.

HALL, Stuart. A identidade cultural na pós-modernidade. Rio de Janeiro: Lamparina, 2015.

MOITA LOPES, Luiz Paulo da. Contemporaneidade e construção de conhecimento na área de estudos linguísticos. SCRIPTA, Belo Horizonte: PPGL/PUC Minas, v. 7, n. 14, p. $159-171,1^{\circ}$ sem. 2004.

MOITA LOPES, Luiz Paulo da. Linguística aplicada e vida contemporânea: Problematização dos construtos que têm orientado a pesquisa. In:

tica aplicada INdisciplinar. 1. ed. São Paulo: Parábola, 2006. p. 85-107.

MOITA LOPES, Luiz Paulo da. Práticas narrativas como espaço de construção das identidades sociais: uma abordagem socioconstrucionista. In: RIBEIRO, Branca Telles; LIMA, Cristina Costa; DANTAS, Maria Tereza Lopes(orgs.). Narrativa, Identidade e Clinica. 1. ed. Rio de Janeiro: Edições IPUB/CUCA, 2001. p. 55-71.

NÓVOA, António (org.). Vidas de Professores. Porto: Porto Editora, 1995.

OLIVEIRA, Luiz Fernandes. O que é uma educação decolonial? Nuevamérica - La revista de la patria grande, Buenos Aires, v. 149, p. 35-39, jan./mar. 2016.

OLIVEIRA, Luiz Fernandes; CANDAU, Vera Maria Ferrão. Pedagogia Decolonial e educação antirracista e intercultural no Brasil. Educação em Revista, Belo Horizonte: Fae/UFMG, v. 26, n. 1, p. 15-40, abr. 2010.

PAIVA, Vera Lúcia Menezes de Oliveira. Manual de pesquisa em estudos linguísticos. São Paulo: Parábola, 2019.

PENNYCOOK, Alastair. Uma linguística aplicada transgressiva. In: MOITA LOPES, Luiz Paulo da (Org.). Por uma linguística aplicada INdisciplinar. 1. ed. São Paulo: Parábola, 2006. p. 67-84. 
RIBEIRO, Djamila. O que é lugar de fala? Belo Horizonte: Letramento, 2017.

VEIGA NETO, Alfredo. A Didática e as experiências de sala de aula: uma visão pós-estruturalista. Revista Educação e Realidade, Porto Alegre: FaE/UFRGS, v. 21, n. 2, p. 161175, jul./dez. 1996

WALSH, Catherine. Pedagogía decoloniales: prácticas insurgentes de resistir, (re) existir y (re) vivir. Tomo I. Quito : Ediciones Abya-Yala, 2013.

WALSH, Catherine. Interculturalidad crítica y educación intercultural. In: Viaña, Jorge Uzieda; Tapia Luis Mealla; (Eds.). Construyendo Interculturalidad Crítica . 1. ed. Bolivia: Instituto Internacional de Integración del Convenio Andrés Bello, 2009. p. 75-96.

Recebido em: 29/04/2020.

Aprovado em: 27/05/2020. 